\title{
LETTER
}

\section{Cyclosporine A prevents cardiac arrest-induced acute respiratory failure: a post-hoc analysis of the CYRUS trial}

\author{
Louis Kreitmann 1,2, Laurent Argaud ${ }^{1,2,3}$, Michel Ovize ${ }^{2,3,4}$, Martin Cour ${ }^{1,2,3^{*}}$ (I) and For the CYRUS Study Group
}

(C) 2020 Springer-Verlag GmbH Germany, part of Springer Nature

Dear Editor,

Accumulating evidence suggests that hypoxemic acute respiratory failure (ARF) is independently associated with poor outcomes in patients successfully resuscitated after out-of-hospital cardiac arrest (OHCA) [1]. This finding opens new therapeutic perspectives, targeting lung injury, to improve the prognosis of OHCA patients. Experimentally, Cyclosporine A (CsA) has been shown to prevent systemic inflammation-induced $\operatorname{ARF}[2,3]$. To investigate the effect of CsA on ARF in the clinical setting, we conducted a post-hoc analysis of the prospective, multicenter, randomized CsA in OHCA resuscitation (CYRUS) trial (ClinicalTrials.gov identifier: NCT01595958).

The CYRUS trial failed to demonstrate a significant decrease in the sequential organ failure assessment (SOFA) score at $24 \mathrm{~h}$ after nonshockable OHCA in patients receiving a prehospital single injection of $2.5 \mathrm{mg} /$ $\mathrm{kg}$ CsA [4]. All the 129 patients alive at $24 \mathrm{~h}$ included in the intention-to-treat analysis (67 in the CsA group and 62 in the control group) were analyzed in the present post-hoc analysis (without correction for multiple comparison), in which the primary endpoint was the occurrence of ARF at $24 \mathrm{~h}$, as defined by a SOFA respiratory sub-score $>2$. The CsA effect was adjusted for history of

\footnotetext{
*Correspondence: martin.cour@chu-lyon.fr

'Service de Médecine Intensive - Réanimation, Hospices Civils de Lyon, Hôpital Edouard Herriot, 5, place d'Arsonval, 69437 Lyon Cedex 03, France Full author information is available at the end of the article
} \section{Springer \\ 实}

respiratory disease, respiratory cause of OHCA and for relevant variables with $p<0.1$ after univariate analysis.

Patient's and OHCA's characteristics were well matched between the two groups (Table 1). At admission, both the median (interquartile) ratio of the arterial partial pressure of oxygen to the fractional inspired oxygen $\left(\mathrm{PaO}_{2} / \mathrm{FiO}_{2}\right)$ and the percentage of patients with ARF did not significantly differ between the CsA and the control groups: 211 (133-319) versus 207 (131-318) $\mathrm{mmHg}$ and $34.3 \%$ versus $32.3 \%$, respectively. At $24 \mathrm{~h}$, ARF was significantly less frequent in the CsA group (29.8\%) compared to the control group (54.8\%) and median $\mathrm{PaO}_{2} /$ $\mathrm{FiO}_{2}$ was $68 \mathrm{mmHg}$ higher in the CsA group (Table 1). Patients treated with CsA were also less likely to fulfill criteria for acute respiratory distress syndrome (Table 1). Importantly, CsA was still independently associated with a lower risk for ARF after multivariate analysis (OR 0.33; 95\%CI [0.16-0.70], $p<0.01$ ) (Supplementary Table 1). This result was confirmed in the per-protocol population of the CYRUS trial (i.e. 61 patients who actually received CsA and 68 patients who did not) by both univariate analysis (ARF in 33\% versus $50 \%$ of patients, respectively, $p<0.05$ ) and multivariate analysis (OR 0.42; 95\%CI [0.20-0.88], $p=0.02$ ).

We report here the first clinical data suggesting that CsA might limit the severity of ARF at $24 \mathrm{~h}$ following OHCA. Even though this post-hoc analysis of the CYRUS trial does not provide mechanistic insight, our findings are in line with both experimental and clinical studies reporting potent protective effects of CsA against ischemia/reperfusion (I/R) injury [1, 2, 3, 5]. CsA may indeed limit I/R-induced cellular damages by inhibiting the cyclophilin D-dependent opening of the mitochondrial permeability transition pore and by 
preserving oxidative phosphorylation [5]. In acute lung injury models, cytoprotection was also attributed to a decrease in circulating mitochondrial pro-inflammatory and pro-apoptotic factors [2, 3]. Studies are now needed to examine the longer-term effects of CsA on lung injury, which could not be done here due to high early mortality rate.

In conclusion, the present study identified CsA as a potential new therapeutic strategy to prevent cardiac arrest-induced ARF. This finding will need further confirmation.

Table 1 OHCA-induced acute respiratory failure

Patients

\begin{tabular}{|c|c|c|c|}
\hline Age (years) & $62.1(52.9-72.7)$ & $63.5(53.8-72.3)$ & 0.651 \\
\hline Male & $42(67.2)$ & $47(75.8)$ & 0.332 \\
\hline History of respiratory disease & $10(14.9)$ & $8(12.9)$ & 0.741 \\
\hline History of cardiac disease & $36(53.7)$ & $35(56.4)$ & 0.756 \\
\hline \multicolumn{4}{|l|}{$\mathrm{OHCA}$} \\
\hline Arrest at place of residence & $40(59.7)$ & $46(74.2)$ & 0.119 \\
\hline Respiratory cause & $22(32.8)$ & $22(35.5)$ & 0.751 \\
\hline Cardiac cause & $33(49.3)$ & $24(38.7)$ & 0.228 \\
\hline Bystander cardiopulmonary resuscitation & $31(46.3)$ & $26(41.9)$ & 0.723 \\
\hline Duration of untreated cardiac arrest (min) & $8(5-12)$ & $10(4-14)$ & 0.340 \\
\hline Time from collapse to ROSC (min) & $35(27-46)$ & $32(24-41)$ & 0.358 \\
\hline Target temperature management & $51(76)$ & $44(71)$ & 0.550 \\
\hline \multicolumn{4}{|l|}{ Cardiovascular dysfunction at $24 \mathrm{~h}$} \\
\hline Mean arterial pressure $(\mathrm{mmHg})$ & $75(64-91)$ & $79(63-89)$ & $>0.99$ \\
\hline Heart rate (beats per min) & $95(75-112)$ & $91(75-105)$ & 0.464 \\
\hline Left ventricular ejection fraction (\%) & $50(30-65)$ & $55(40-60)$ & 0.899 \\
\hline Vasoactive drugs & $43(64.2)$ & $39(62.9)$ & 0.880 \\
\hline \multicolumn{4}{|l|}{ Respiratory dysfunction at $24 \mathrm{~h}$} \\
\hline Mechanical ventilation & $67(100)$ & $62(100)$ & N/A \\
\hline \multicolumn{4}{|l|}{ Ventilator settings } \\
\hline $\mathrm{FiO}_{2}(\%)$ & $40(35-60)$ & $50(40-70)$ & 0.230 \\
\hline $\operatorname{PEEP}\left(\mathrm{cmH}_{2} \mathrm{O}\right)$ & $5(4-6)$ & $5(5-6)$ & 0.278 \\
\hline Tidal volume $(\mathrm{mL} / \mathrm{kg})$ & $6.6(6.1-8.2)$ & $6.4(5.8-7.9)$ & 0.593 \\
\hline Minute ventilation (L/min) & $10.6(8.5-12.6)$ & $10.7(7.8-12.8)$ & 0.749 \\
\hline Sedation/curarization & $42(62.7)$ & $30(48.4)$ & 0.102 \\
\hline Chest quadrants with infiltrates & $2(1-3)$ & $2(1-4)$ & 0.522 \\
\hline \multicolumn{4}{|l|}{ Arterial blood gases } \\
\hline $\mathrm{pH}$ & $7.32(7.24-7.41)$ & $7.36(7.29-7.43)$ & 0.116 \\
\hline $\mathrm{PaCO}_{2}(\mathrm{mmHg})$ & $36(31-42)$ & $35(32-41)$ & 0.914 \\
\hline $\mathrm{PaO}_{2}(\mathrm{mmHg})$ & $104(82-135)$ & $91(77-121)$ & 0.103 \\
\hline $\mathrm{PaO}_{2} / \mathrm{FiO}_{2}(\mathrm{mmHg})^{*}$ & $255(180-337)$ & $187(125-304)$ & 0.021 \\
\hline Lactate (mmol/L) & $2.8(1.7-4.5)$ & $3.0(1.9-5.1)$ & 0.603 \\
\hline Acute respiratory failure $^{\dagger}$ & $20(29.8)$ & $34(54.8)$ & 0.019 \\
\hline Acute respiratory distress syndrome ${ }^{\ddagger}$ & $5(7.4 \%)$ & $11(17.7 \%)$ & 0.108 \\
\hline
\end{tabular}

Data are expressed as median (interquartile range) or number (\%) and compared using Wilcoxon, chi-square or Fisher's exact tests, as appropriate OHCA out-of-hospital cardiac arrest, ROSC restoration of spontaneous circulation, SOFA sequential organ failure assessment score, $P E E P$ positive end-expiratory pressure, $\mathrm{PaCO}_{2}$ arterial partial pressure of carbon dioxide, $\mathrm{PaO}_{2} / \mathrm{FiO}_{2}$ ratio of the arterial partial pressure of oxygen to the fractional inspired oxygen

*Imputed, if needed, using adjusted pulse saturation of oxygen $\left(\mathrm{SpO}_{2}\right)$ to $\mathrm{FiO}_{2}$ ratio $(\mathrm{n}=2$ patients in the control group)

+ Defined as $\mathrm{PaO}_{2} / \mathrm{FiO}_{2}$ ratio $<200 \mathrm{mmHg}$ in mechanically ventilated patients

₹ Defined according to Berlin criteria 
Electronic supplementary material

The online version of this article (https://doi.org/10.1007/s00134-020-06043-0)

contains supplementary material, which is available to authorized users.

\section{Author details}

1 Service de Médecine Intensive - Réanimation, Hospices Civils de Lyon, Hôpital Edouard Herriot, 5, place d'Arsonval, 69437 Lyon Cedex 03, France. ${ }^{2}$ Faculté de médecine Lyon Est, Université de Lyon, Université Claude Bernard Lyon 1, 69373 Lyon, France. ${ }^{3}$ INSERM, U1060 CarMeN, 69373 Lyon, France. ${ }^{4}$ Service d'Explorations Fonctionnelles Cardiovasculaire, Centre d'Investigations Cliniques, Hôpital Cardiologique Louis Pradel, Bron, France.

\section{Acknowledgments}

Co-investigators of the CYRUS study group: Pierre-Yves Gueugniaud (CHU de Lyon); Fabrice Zéni (CHU de Saint-Etienne); Xavier Tchénio (CH de Bourg-enBresse); Jean-Pierre Quenot (CHU de Dijon); Pascal Beuret (CH de Roanne); Michel Badet (CH de Chambéry); Kevin Chaulier (CH de Villefranche); Quentin Blanc ( $\mathrm{CH}$ de Valence); Bénédicte Vallet ( $\mathrm{CH}$ de Beaunes); Marc Gainnier ( $\mathrm{CHU}$ de Marseille); Emel Alasan (CH Annonay); Sonia Sadoune (CHU de Nancy); Xavier Bobbia (CHU de Nîmes)

\section{Funding}

This study was funded by the Programme Hospitalier de Recherche Clinique Inter-régional 2009 from the French Ministry of Health and by the grant Jeune Chercheur Hospitalier 2010 from the Hospices Civils de Lyon.

\section{Compliance with ethical standards}

\section{Conflicts of interest}

The authors declare that they have no conflict of interest.

\section{Ethical approval}

All procedures performed in studies involving human participants were in accordance with the ethical standards of our institutional research committee and with the 1964 Declaration of Helsinki and its later amendments. The study was approved by the institutional review board (Comité de Protection des Personnes Sud-Est IV, France), and written informed consent for participation in the study was obtained for all patients.

\section{Publisher's Note}

Springer Nature remains neutral with regard to jurisdictional claims in published maps and institutional affiliations.

Accepted: 6 April 2020

Published online: 21 April 2020

\section{References}

1. Johnson NJ, Caldwell E, Carlbom DJ, Gaieski DF, Prekker ME, Rea TD, Sayre M, Hough CL (2019) The acute respiratory distress syndrome after out-ofhospital cardiac arrest: Incidence, risk factors, and outcomes. Resuscitation 135:37-44. https://doi.org/10.1016/j.resuscitation.2019.01.009

2. Li J, Yan Z, Fang Q (2017) A mechanism study underlying the protective effects of cyclosporine-A on lung ischemia-reperfusion injury. Pharmacology 100:83-90. https://doi.org/10.1159/00048760

3. Xiao Z, Jia B, Zhao X, Bi S, Meng W (2018) Attenuation of lipopolysaccharide-induced acute lung injury by cyclosporine-A via suppression of mitochondrial DNA. Med Sci Monit 24:7682-7688. https://doi. org/10.12659/MSM.909909

4. Argaud L, Cour M, Dubien PY, Giraud F, Jossan C, Riche B, Hernu R, Darmon M, Poncelin Y, Tchénio X, Quenot JP, Freysz M, Kamga C, Beuret P, Usseglio P, Badet M, Anette B, Chaulier K, Alasan E, Sadoune S, Bobbia X, Zéni F, Gueugniaud PY, Robert D, Roy P, Ovize M, CYRUS Study Group (2016) Effect of cyclosporine in nonshockable out-of-hospital cardiac arrest: the CYRUS randomized clinical trial. JAMA Cardiol 1:557-565. https ://doi.org/10.1001/jamacardio.2016.1701

5. Cour M, Loufouat J, Paillard M, Augeul L, Goudable J, Ovize M, Argaud L (2011) Inhibition of mitochondrial permeability transition to prevent the post-cardiac arrest syndrome: a pre-clinical study. Eur Heart J 32:226-335. https://doi.org/10.1093/eurheartj/ehq112 